Published in "The Journal of Physical Chemistry C

112(32): 12104-12110, 2008"

which should be cited to refer to this work.

\title{
Amino Acids in Iron Oxide Mineralization: (Incomplete) Crystal Phase Selection Is Achieved Even with Single Amino Acids
}

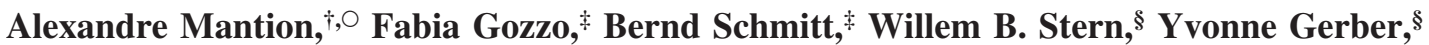 \\ Adeline Y. Robin," Katharina M. Fromm, ${ }^{\perp}$ Monika Painsi, ${ }^{\#}$ and Andreas Taubert $*, \dagger, \nabla$ \\ Department of Chemistry, University of Basel, CH-4056 Basel, Switzerland, Swiss Light Source, \\ Paul-Scherrer-Institute, CH-5232 Villigen, Switzerland, Department of Environmental Geosciences, University \\ of Basel, CH-4056 Basel, Switzerland, Laboratoire de cristallogénèse et cristallographie des protéines, Institut \\ de Biologie Structurale Jean-Pierre Ebel, CEA-CNRS-University J. Fourier, F-38027 Grenoble, France, \\ Department of Chemistry, University of Fribourg, CH-1700 Fribourg, Switzerland, Institute of Geological \\ Sciences, University of Bern, CH-3012 Berne, Switzerland, Institute of Chemistry, University of Potsdam, \\ D-14476 Golm, Germany, and Max-Planck-Institute of Colloids and Interfaces, D-14476, Golm, Germany
}

Iron oxides are important minerals in biology and materials science. Using biomimetic synthesis, a variety of iron oxides have been fabricated. However, it is still not clear how growth modifiers like amino acids and peptides select different crystal phases of a complex material like iron oxide. The current paper shows that already with single amino acids, (incomplete) crystal phase selection is achieved in vitro. In particular, L-histidine, L-threonine, and L-cysteine favor the formation of unstable crystal phases like ferrihydrite or lepidocrocite, although sometimes only at high amino acid concentrations. Other amino acids like L-valine have only minor effects when compared to control samples grown in the absence of amino acids. The effects of the amino acids can be rationalized via kinetic trapping and different interaction strengths of the amino acids with the growing iron oxide particles. The effects of the amino acids on the particle morphologies are less significant. The paper therefore shows that single amino acids can be a valuable tool for the materials chemist to fabricate and stabilize even unstable iron oxide crystal phases.

\section{Introduction}

Iron oxides and hydroxides are among the most important minerals in biology and technology. ${ }^{1-4}$ Biomimetic iron oxide particles have been made from a range of iron salts, and a wide variety of particles, including functionalized particles for nanomedicine, has been obtained. ${ }^{4-8}$ Despite the successful implementation in several branches of technology, the details of iron oxide mineralization both in vivo and in vitro are a subject of ongoing research. ${ }^{9-22}$ For example, Mann et al. have studied the formation of iron oxides and oxyhydroxides using phospholipid vesicles as a model system. ${ }^{9}$ Banfield and coworkers have studied the mineralization of iron oxides on a polymer-based scaffold and have suggested reasons why some microbes release polysaccharide-templated iron oxohydroxides. ${ }^{15,16}$ The thermochemistry of iron oxides and oxyhydroxides is also still under investigation, ${ }^{12,23}$ in particular interconversion processes. . $^{13,14,17-19}$

There is little knowledge on how peptides and other biological or organic molecules control iron oxide mineralization. However, there are some data on the interaction of organic molecules

\footnotetext{
* Corresponding author. Phone: ++49(0)331977 5773.E-mail: ataubert@ uni-potsdam.de.

${ }^{\dagger}$ Department of Chemistry, University of Basel.

\$ Paul-Scherrer-Institute.

$\S$ Department of Environmental Geosciences, University of Basel.

"CEA-CNRS-University J. Fourier.

${ }^{\perp}$ University of Fribourg.

\# University of Bern.

$\nabla$ University of Potsdam and Max-Planck-Institute of Colloids and Interfaces.

${ }^{\circ}$ Current address: Department of Chemistry, Humboldt University, Brook-Taylor-Str. 2, D-12489 Berlin, Germany.
}

with preformed iron oxide particles. Brown has shown that proteins containing a basic oligopeptide, Arg-Arg-Val-Thr-LysHis-His-Val-Asn, adsorb on $\mathrm{Fe}_{2} \mathrm{O}_{3}$ but not on $\mathrm{Fe}_{3} \mathrm{O}_{4}{ }^{24,25}$ Arakaki et al. have found an acidic protein tightly bound to magnetite, $\mathrm{Fe}_{3} \mathrm{O}_{4} \cdot{ }^{26}$ Prozorov et al. have shown that the same protein induces the formation of magnetic nanoparticles. ${ }^{27}$ Matrajt and Blanot have shown that different amino acids interact differently with ferrihydrite. ${ }^{28}$ Similar interactions exist for other inorganic/ peptide combinations, ${ }^{29}$ but even the mineralization of a simple compound like $\mathrm{ZnO}$ is more complex with peptides ${ }^{30,31}$ than with synthetic polymers. ${ }^{32-34}$ As a result, there is a need to further study the role of biomimetic additives on the mineralization of iron oxides.

The current work is inspired by the work of Brown, who has shown that the oligopeptide Arg-Arg-Val-Thr-Lys-His-His-ValAsn adsorbs on $\mathrm{Fe}_{2} \mathrm{O}_{3}$ but not on $\mathrm{Fe}_{3} \mathrm{O}_{4} .{ }^{24}$ In order to determine if there is already an effect of the individual components of this oligopeptide (that is, the single amino acids), we have precipitated iron oxide in the presence of different concentrations of these amino acids. For comparison, we have also included the sulfur-containing amino acids L-cysteine and L-methionine, which are known to strongly coordinate to iron. ${ }^{35}$ The paper clearly shows that already single amino acids have a strong influence on iron oxide crystal phase selection from aqueous solution, although there is no complete suppression of other crystal phases.

\section{Experimental Section}

Preparation of Iron Oxides. Chemicals were obtained from Fluka and used as received. For precipitation, $50 \mathrm{~mL}$ of an aqueous amino acid solution and $20 \mathrm{~mL}$ of an aqueous $80 \mathrm{mM}$ 

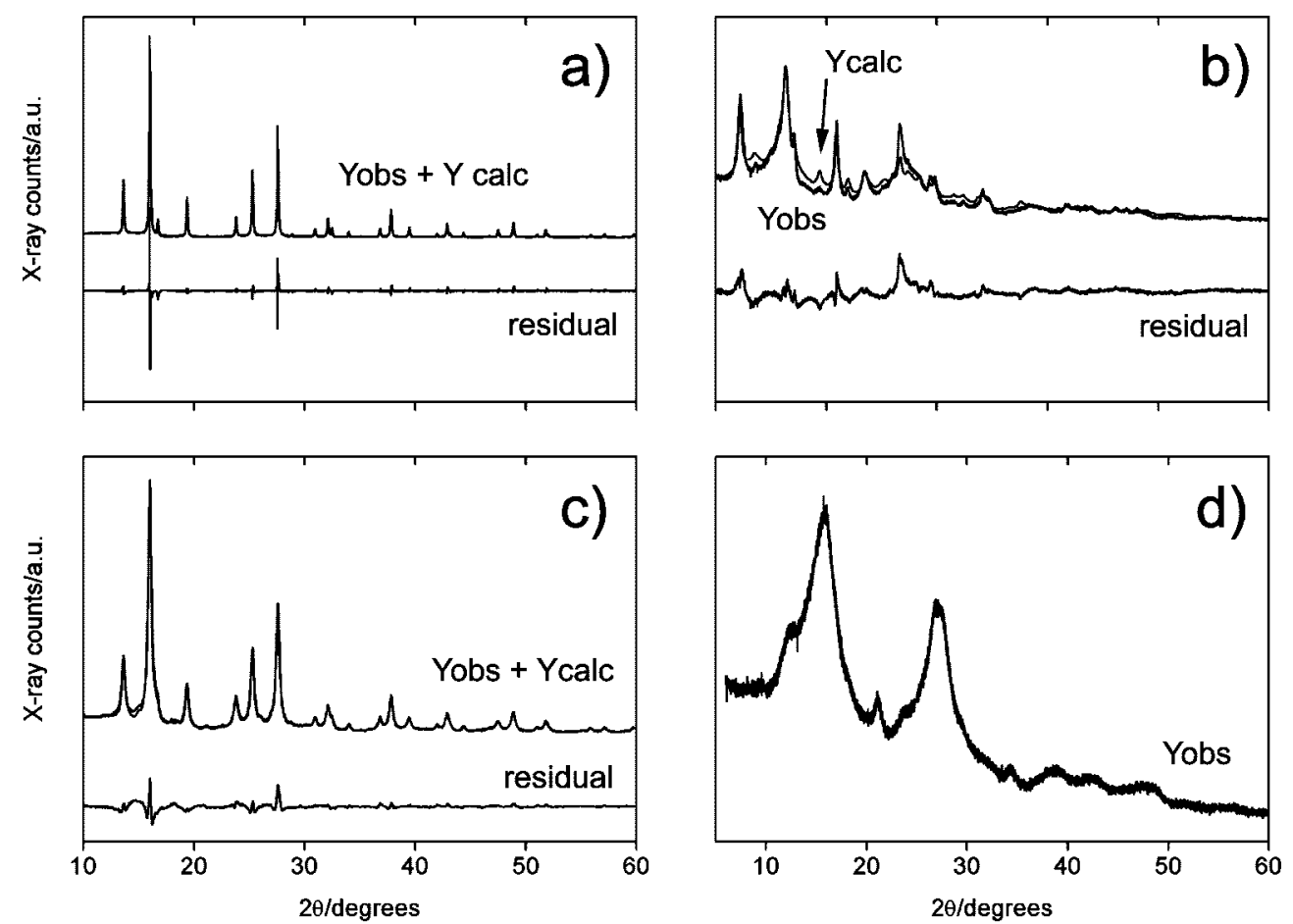

Figure 1. Representative X-ray patterns and Rietveld refinement of samples precipitated in the presence of (a) L-valine (1 mM), (b) L-asparagine $(80 \mathrm{mM})$, (c) L-arginine $(10 \mathrm{mM})$, and $(\mathrm{d}) \mathrm{L}$-threonine $(80 \mathrm{mM})$. The peak width affects the quality of the refinement. The peaks in panel $\mathrm{d}$ are too broad for a successful refinement. The residual curve is a measure of the quality of the fit. For clarity reasons, the JCPDS peak positions of the respective iron oxides are not displayed. For crystal phases of the respective samples see Table 1.

$\mathrm{FeSO}_{4}\left(\mathrm{NH}_{4}\right)_{2} \mathrm{SO}_{4} \cdot 6 \mathrm{H}_{2} \mathrm{O}$ solution were mixed under stirring. Then $10 \mathrm{~mL}$ of a $12 \mathrm{M}$ aqueous ammonia solution were added under stirring. Amino acid concentrations were set such that the final concentration after mixing these solutions was $0.1,1$, 10 , or $100 \mathrm{mM}$. In the case of histidine and threonine, the maximum concentrations were 60 and $80 \mathrm{mM}$, respectively, due to their limited solubility. During the whole process, air was bubbled through the reaction solution with an aquarium pump at $10 \mathrm{~L} / \mathrm{hr}$. During reaction, the $\mathrm{pH}$ remained at $\mathrm{pH}$ 9. After $24 \mathrm{~h}$, the suspensions were centrifuged, the supernatant was decanted, and the solids were air-dried at $40{ }^{\circ} \mathrm{C}$.

Characterization. XRD was done at the Swiss Light Source, Paul-Scherrer-Institute, Beamline X04SA. Patterns were recorded from $1^{\circ}$ to $60^{\circ} 2 \theta$ using the MYTHEN microstrip detector. ${ }^{36}$ Samples were mounted in $1 \mathrm{~mm}$ mark tubes (Hilgendorf) and measured while rotating. X-ray wavelength $\lambda$ was $0.708 \AA$ and electron energy was $17.5 \mathrm{keV}$. Peaks were modeled using a Pseudo Voigt model (Thompson-Cox-Hastings pseudo-Voigt convoluted with Axial divergence asymmetry) using Fullprof. ${ }^{37}$ Atomic positions were used as published. ${ }^{3}$ For TEM, particles were dispersed in ethanol and deposited on carbon coated copper grids. Samples were imaged with a Philips Morgagni TEM at $80 \mathrm{kV}$. TGA was done on a Mettler Toledo TGA/SDTA851e from 25 to $600{ }^{\circ} \mathrm{C}$ with heating rates of $10-40$ ${ }^{\circ} \mathrm{C} / \mathrm{min}$ under nitrogen $(10 \mathrm{~mL} / \mathrm{min})$ in alumina crucibles. IR spectra were recorded on a Shimadzu FTIR 8300 with a Golden Gate ATR probe from 650 to $4000 \mathrm{~cm}^{-1}$. Raman microscopy was done with an Olympus BX 41 (100 x objective) optical microscope coupled to a Labram HR800 Jobin Yvon Horiba Raman spectrometer with a $514 \mathrm{~nm}$ laser with a power of 5.20 $\mathrm{mW}$. XRF spectra were recorded on an energy-dispersive Spectro X-LABORATORY 2000 using the "police tape" method.

\section{Results}

Crystal phases of the precipitates were determined via synchrotron powder X-ray diffraction (XRD). Rietveld refinement was used to determine the relative amounts of individual crystal phases present in each sample. Figure 1 shows representative XRD patterns. Already visual inspection of the patterns shows that there are big differences between individual samples. Some samples appear well crystallized, which is indicated by the rather narrow reflections, whereas others are so poorly crystalline that Rietveld refinement was only possible with rather large errors or not possible at all.

Table 1 and Figure 2 summarize the results from XRD and Rietveld refinement. Overall, the precipitates can be classified in two groups, which are plotted as the left and right column of Figure 2, respectively. Figure 2 shows that L-valine, Lmethionine, L-asparagine, and L-arginine have a similar effect on mineralization. At low amino acid concentration, the sample is over $95 \%$ magnetite. Only with L-arginine, at $10 \mathrm{mM}$, a small fraction of goethite is found. At $100 \mathrm{mM}$ of amino acid, other crystal phases are present in significant amounts: L-valine and L-methionine lead to mixtures of magnetite and lepidocrocite, whereas in the presence of L-asparagine and L-arginine mixtures of magnetite, goethite, and lepidocrocite form. Furthermore, the weight fraction of magnetite decreases from L-valine to Larginine and the fraction of goethite and the fraction of the less stable lepidocrocite increases.

The second group of precipitates does not exhibit as clear trends, but a few features can be found: L-lysine differs from the aforementioned samples in that already at $10 \mathrm{mM}$ of amino acid, a significant decrease in the magnetite content and corresponding increase in goethite content is found. At $100 \mathrm{mM}$, goethite is replaced by lepidocrocite and the magnetite fraction further decreases. At this point, it is interesting to compare the samples precipitated with L-asparagine, L-arginine, and L-lysine: 
TABLE 1: Iron Oxide Composition (wt \%) as a Function of the Amino Acid (AA) ${ }^{a}$

\begin{tabular}{|c|c|c|c|c|c|c|}
\hline amino acid & $1 \mathrm{mM}$ & $\%$ & $10 \mathrm{mM}$ & $\%$ & $100 \mathrm{mM}^{b}$ & $\%$ \\
\hline \multirow[t]{3}{*}{ L-valine } & magnetite & 100 & magnetite & 100 & magnetite & 55 \\
\hline & & & & & goethite & 1 \\
\hline & & & & & lepidocrocite & 44 \\
\hline \multirow{2}{*}{ L-lysine } & & & goethite & 35 & goethite & 1 \\
\hline & & & & & lepidocrocite & 50 \\
\hline L-methionine & magnetite & 100 & magnetite & 98 & magnetite & 40 \\
\hline \multirow[t]{3}{*}{ L-asparagine } & magnetite & 97 & magnetite & 100 & magnetite & 29 \\
\hline & goethite & 3 & & & goethite & 17 \\
\hline & & & & & lepidocrocite & 54 \\
\hline \multirow[t]{3}{*}{ L-arginine } & magnetite & 100 & magnetite & 91 & magnetite & 2 \\
\hline & & & goethite & 9 & goethite & 31 \\
\hline & & & & & lepidocrocite & 66 \\
\hline \multirow{2}{*}{ L-cysteine } & goethite & 34 & & & & \\
\hline & lepidocrocite & 63 & lepidocrocite & 100 & lepidocrocite/cystine hybrid ${ }^{d}$ & $\mathrm{~N} / \mathrm{a}$ \\
\hline
\end{tabular}

${ }^{a}$ The control sample is composed of $94 \%$ magnetite and $6 \%$ goethite. Representative X-ray patterns are given in Figure 1, crystallite sizes in Table 2, and stress-strain data are given in the Supporting Information, Table S2. ${ }^{b}$ Maximum concentrations are $80 \mathrm{mM}$ for L-threonine and $60 \mathrm{mM}$ for L-histidine due to solubility limits. ${ }^{c}$ These reflections are too broad for Rietveld refinement. Minor amounts of other crystal phases may have gone undetected. ${ }^{d}$ See discussion below.
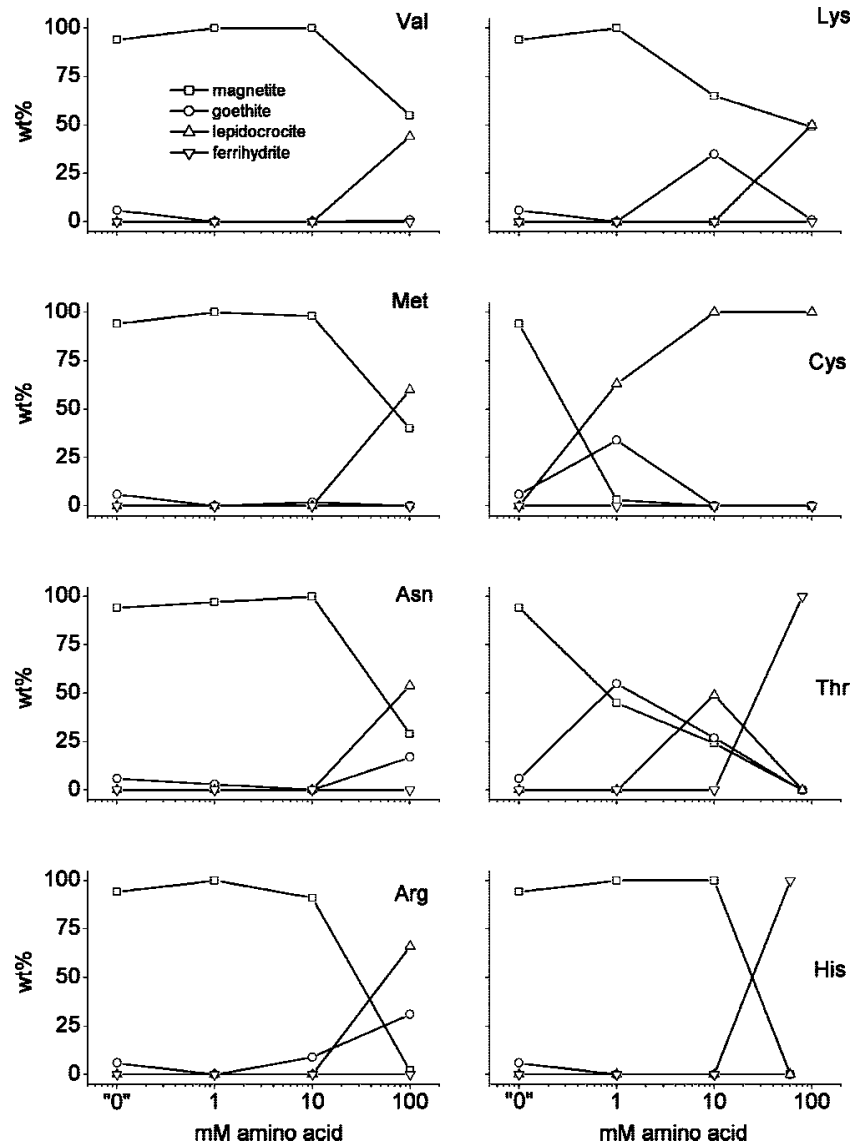

Figure 2. Phase composition of the precipitate as a function of the amino acid chemistry and concentration. " 0 " denotes the control sample (no amino acid), which, for simplicity of data representation, was also kept on the log scale of the $x$ axis. For experimental values, see Table S1.

these amino acids are more efficient stabilizers for metastable crystal phases in increasing order. L-asparagine only leads to a small fraction of goethite and lepidocrocite at high amino acid concentration. The fraction of these two crystal phases increases further with L-arginine and finally L-lysine. Moreover, L-lysine has this effect at lower concentration.

L-Cysteine shows the same trend as L-lysine, but is more efficient in that it already at low concentrations of $1 \mathrm{mM}$ reduces the amount of magnetite to close to zero. L-Cysteine efficiently traps goethite and lepidocrocite at $1 \mathrm{mM}$ and exclusively stabilizes lepidocrocite at 10 and $100 \mathrm{mM}$. Similar to L-cysteine, L-threonine leads to goethite at $1 \mathrm{mM}$, lepidocrocite at $10 \mathrm{mM}$, and 2-line ferrihydrite at $100 \mathrm{mM}$. L-Histidine is exotic in that it does not appear to have an impact on the mineralization until at high concentrations of $100 \mathrm{mM}$. However, at this concentration, the rather unstable ferrihydrite forms exclusively.

The above results clearly show that amino acids trap kinetically favored iron oxide crystal phases. The amino acids can be roughly arranged in order of increasing trapping efficiency. On this scale, L-valine is the least efficient additive, followed by L-methionine, L-asparagine, L-arginine, L-lysine, L-cysteine, and finally L-threonine. The latter two stabilize lepidocrocite and ferrihydrite, respectively, at high concentrations, but they also trap goethite and lepidocrocite at concentrations as low as $1 \mathrm{mM}$.

Figure 3 shows representative transmission electron microscopy (TEM) images of some samples. Control samples and samples precipitated with $1 \mathrm{mM}$ of amino acid (predominantly) contain rounded particles with a broad size distribution. At 10 and $100 \mathrm{mM}$, the morphologies vary. The particle morphologies are only poorly defined and in many cases large aggregates are observed and the sizes of the individual particles vary significantly within the sample as well as between the samples. This is in contrast to for example $\mathrm{ZnO}$ where both synthetic polymers and short peptides lead to well-defined particles with a narrow size distribution. ${ }^{30-33,38,39}$ TEM therefore shows that the amino acids used as growth modifiers are inefficient in the sense that no uniform particle morphology and particle size is obtained. 

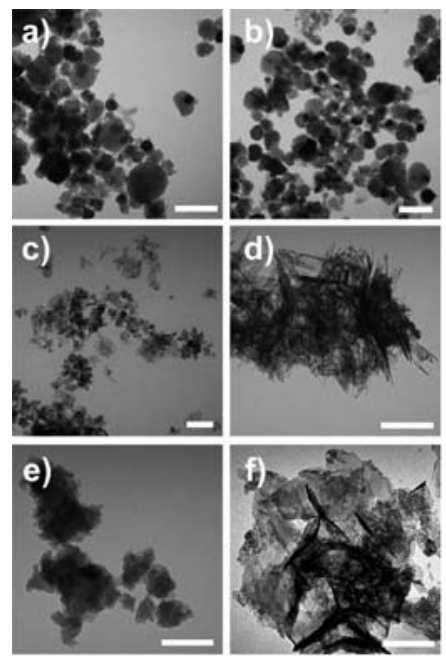

Figure 3. TEM images of (a) control sample (magnetite + goethite), (b) L-lysine $1 \mathrm{mM}$ (magnetite), (c) L-lysine $10 \mathrm{mM}$ (magnetite + goethite), (d) L-lysine $100 \mathrm{mM}$ (magnetite + goethite + lepidocrocite), (e) L-histidine $60 \mathrm{mM}$ (ferrihydrite), and (f) L-methionine $100 \mathrm{mM}$ (magnetite + lepidocrocite). Scale bars are $100 \mathrm{~nm}$. For fractions of crystal phases see Table 1 .

Figure 4 shows that, in the presence of $1 \mathrm{mM}$ of L-cysteine, the samples consist of plates and aggregated, parallel rods. At $10 \mathrm{mM}$, the precipitates form wires. At $100 \mathrm{mM}$, TEM reveals large platelets with irregular shapes. Some particles show Moiré patterns or bend contours, demonstrating that they are thin crystalline flakes. TEM therefore again shows that the particle morphology is not controlled by the amino acids. This means that again a wide range of particle sizes and at lower L-cysteine concentration also a wide range of particle shapes is observed.

Synchrotron XRD of these samples shows a set of sharp reflections that can be assigned to L-cystine, that is, the oxidized, dimeric form of L-cysteine. Closer inspection of the XRD patterns also reveals very weak and broad reflections at 6.3, $12.2,16.3$, and 21.1 degrees $2 \theta$ that can be assigned to the lepidocrocite 200, 210, 301, and 020 reflections (JCPDS 44-1415), respectively. XRD thus suggests that here an organic solid containing a small fraction of the inorganic lepidocrocite forms.

Raman spectroscopy, Figure 5, confirms the presence of L-cystine in the precipitates obtained with L-cysteine as a starting material. Besides the signals assigned to L-cystine, the spectrum also shows a peak at 250 and a shoulder at $377 \mathrm{~cm}^{-1}$, which can be assigned to lepidocrocite..$^{40,41}$ Moreover, X-ray fluorescence (XRF) shows that the sample contains only ca. $5 \%$ of Fe (from lepidocrocite) and ca. 36\% of S (from L-cystine). This is consistent with Raman and XRD data, which also indicate a large amount of organic material. The (molar) organic fraction is 5- to 6-fold larger than the inorganic fraction. Thermogravimetric analysis (TGA) further confirms these findings. As a result, Raman, XRF, TGA, and XRD show that the precipitate is an L-cystine/lepidocrocite composite with a high organic fraction.

Amino acid incorporation in the precipitates has been further studied with IR spectroscopy and thermogravimetric analysis (TGA). Figure 6 shows representative TGA curves of a series of samples precipitated with L-lysine. The control sample and samples precipitated from $1 \mathrm{mM}$ solutions only exhibit a minor weight loss, typically less than $0.5 \%$, which is presumably due to water desorption. Samples precipitated with L-threonine and L-cysteine (with the exception of $100 \mathrm{mM}$ L-cysteine, see above)
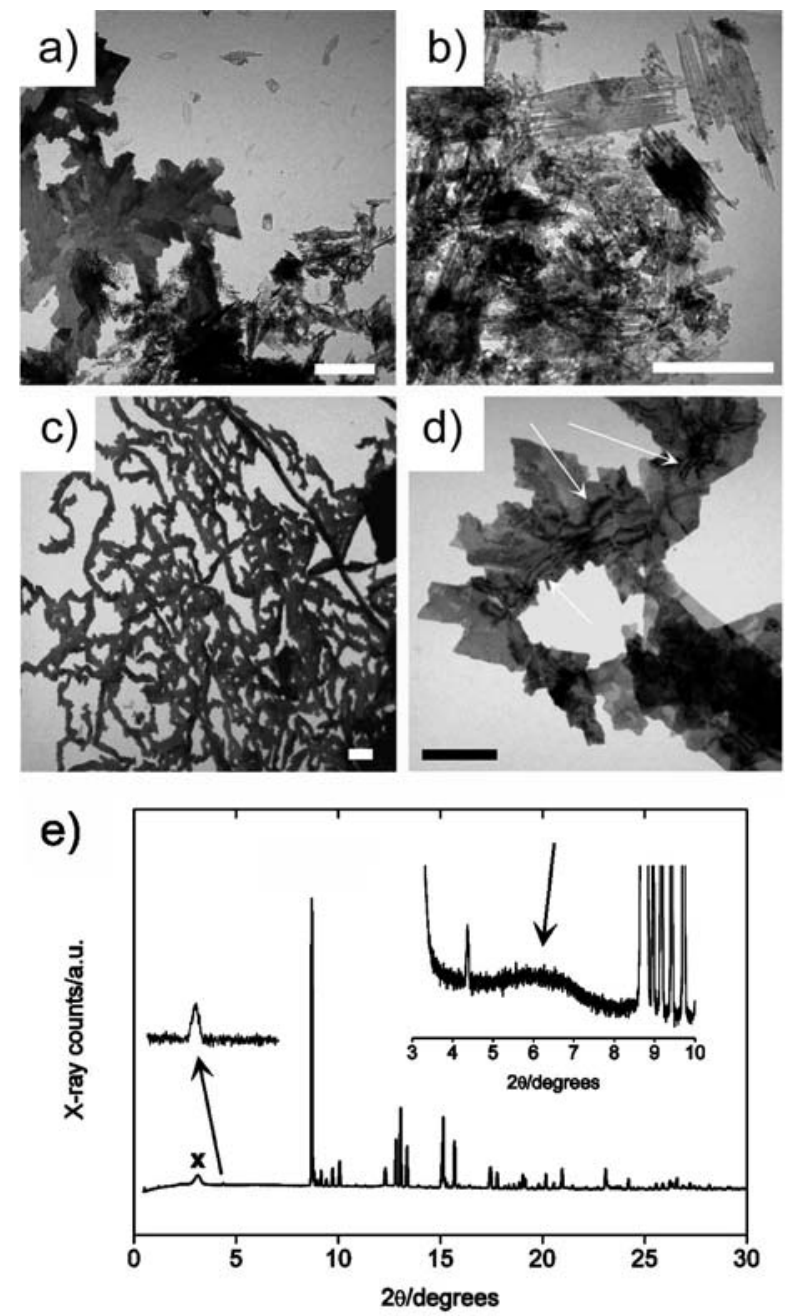

Figure 4. TEM images of precipitates formed in the presence of L-cysteine. (a, b) $1 \mathrm{mM}$, (c) $10 \mathrm{mM}$, and (d) $100 \mathrm{mM}$. Scale bars are $250 \mathrm{~nm}$. Dark lines (arrows) are bend contours. (e) X-ray pattern of a sample precipitated from a $100 \mathrm{mM}$ L-cysteine solution; ( $\mathrm{x}$ ) is a peak from the sample support. Inset: very broad lepidocrocite 200 reflection at 6.3 degrees $2 \theta$ (arrow).

and all samples precipitated with higher amino acid concentrations typically exhibit several broad transitions in TGA (labeled 1,2 , and 3 in Figure 6). The samples lose $3-5 \%$ at $70-80{ }^{\circ} \mathrm{C}$, followed by an additional loss between 200 and $280{ }^{\circ} \mathrm{C}$, depending on the amino acid (and hence the crystal phases of the original sample). Finally, often a weight loss between 300 and $380{ }^{\circ} \mathrm{C}$ that again depends on the amino acid is observed. We assign the first weight loss to water leaving the sample. The two latter losses are assigned to decomposition of the amino acids and iron oxide phase transitions to thermodynamically more stable phases, which is accompanied by dehydration. The width of the transitions however, suggests that the individual processes strongly overlap, and it is therefore difficult to draw more detailed conclusions. XRD however supports this interpretation as we only find hematite after annealing at $400{ }^{\circ} \mathrm{C}$. This shows that a dehydration and phase transition is involved in the processes observed here.

Figure 7 shows IR spectra of a control sample and a sample precipitated with L-lysine. IR spectroscopy confirms the findings from TGA and (where applicable) Raman spectroscopy as the samples precipitated with amino acids clearly show the presence of organic moieties in the precipitates. Furthermore, many IR spectra show a significant $-\mathrm{OH}$ vibration at around $3000-3100$ 

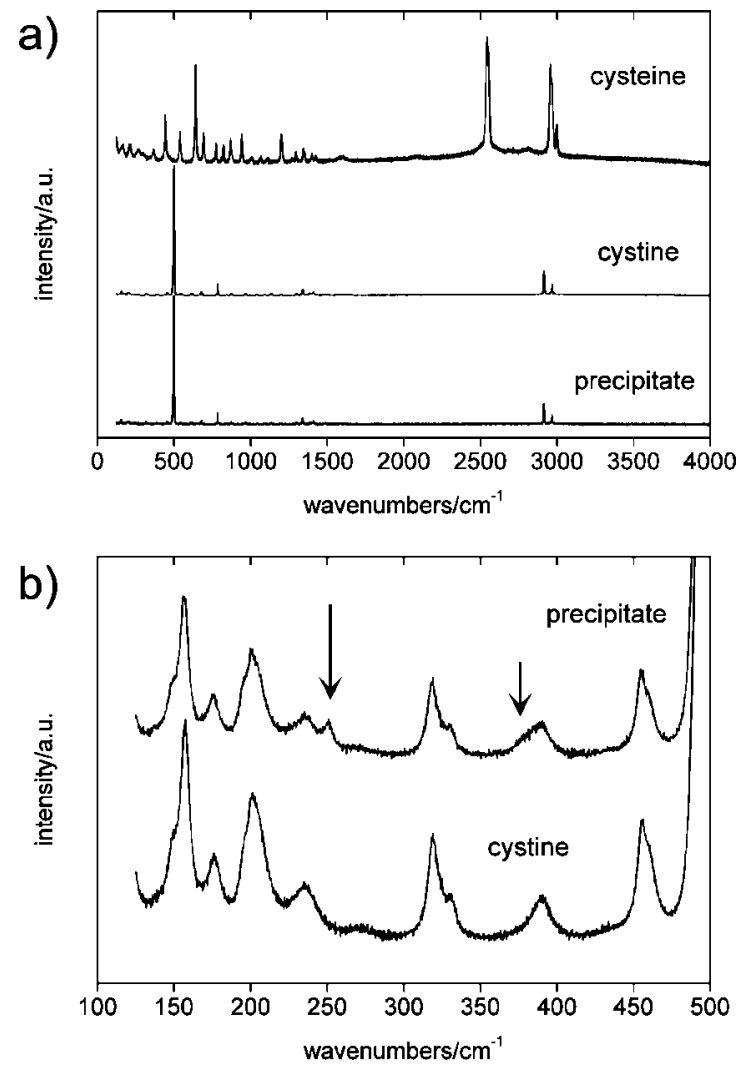

Figure 5. (a) Raman spectra of L-cysteine, L-cystine, and the precipitate. (b) Low wavenumber region. Arrows point to lepidocrocite peak and shoulder.

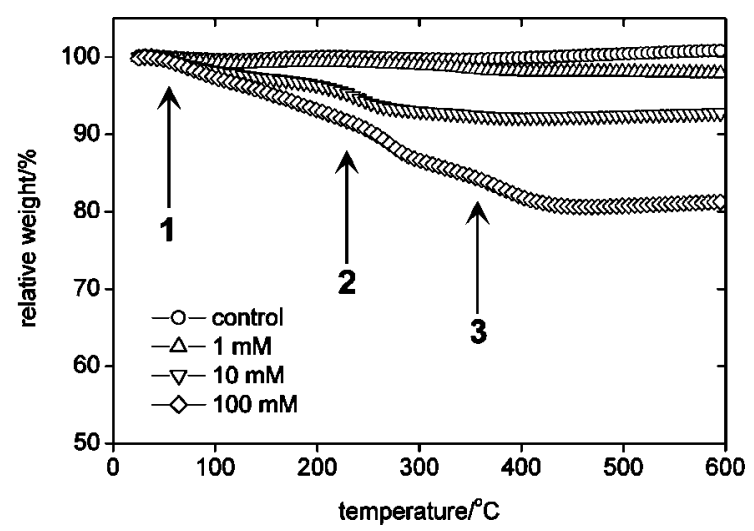

Figure 6. TGA curves of a control sample and samples precipitated with 1,10 , and $100 \mathrm{mM}$ of L-lysine. Note that the $y$ axis is only from 50 to $105 \%$ relative weight.

$\mathrm{cm}^{-1}$. This band is assigned to both water incorporated into the crystal (lattice), in particular in the case of the hydrated iron oxides, and to adsorbed surface water.

\section{Discussion}

The current data provide some basic insight into the effect of single amino acids on the precipitation of iron oxide nanoparticles in vitro. First and foremost, the data show that the different amino acids change the crystal phase of the resulting precipitates. Although the effect is not strong enough to lead to single phase materials, some amino acids have a pronounced effect in that they stabilize large fractions of otherwise unstable crystal phases like ferrihydrite.

Commonly, organic growth modifiers are claimed to adsorb onto growing (inorganic) particles, and indeed, an adsorption-

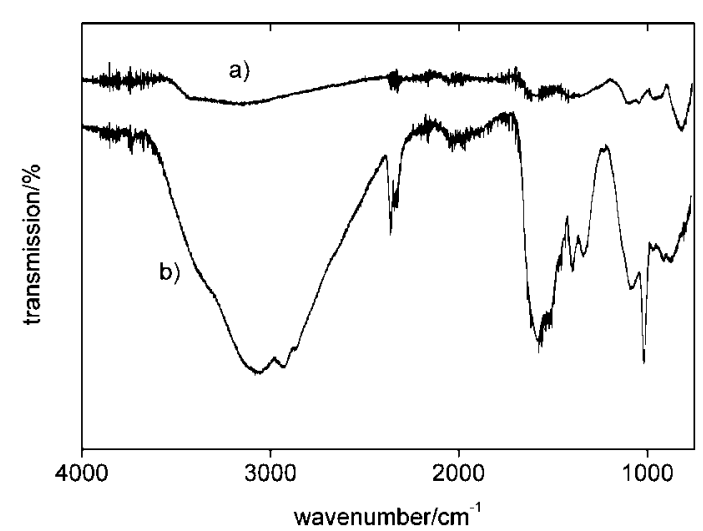

Figure 7. Representative IR spectra of a control sample (a) and a sample precipitated with $100 \mathrm{mM}$ of L-lysine (b). The spectra are drawn to scale and clearly show that some organic components are incorporated into the sample (b).

mediated process can also be postulated here. There are two plausible processes that can in principle lead to the observed effects: (1) The amino acids adsorb on the surface of a particle with a given crystal phase as it precipitates. The adsorbed amino acids then prevent redissolution/reprecipitation ${ }^{3}$ of the respective particles. Alternatively, (2) the amino acids adsorb on the surface of the first precipitate and then change the redissolution/ reprecipitation process such that different crystal phases form. Matrajt and Blanot have shown that amino acid adsorption on ferrihydrite differs significantly between different amino acids. ${ }^{28}$ We therefore postulate that in the current study, the amino acids show an amino acid-specific (or at least partially specific) adsorption onto particles with different crystal phases. As some amino acids have a higher affinity for metastable phases, they (partly) kinetically trap these phases.

L-Valine and L-methionine have little or no effect on the crystal phase when compared to the control samples. This suggests that there is only a weak interaction (regardless of the type of interaction) between the precipitates and these amino acids. As a result, the crystallization proceeds almost as in the absence of growth modifier.

The other amino acids have significant effects on the mineralization. At high concentrations $(100 \mathrm{mM})$, the strongest effects are observed. With L-arginine, L-lysine, and L-threonine the fractions of metastable crystal phases increase in that order. That is, these amino acids increasingly stabilize metastable precipitates. Moreover, the metastable crystal phases are stabilized at lower amino acid concentrations than with L-valine and L-methionine. This especially applies to L-threonine and clearly shows that the interaction strength of amino acids and iron oxide particles increases from L-asparagine to L-threonine. L-Histidine is somewhat special, because it only affects crystal phase formation at rather high concentration.

The different behavior of the three basic amino acids L-lysine, L-arginine, and L-histidine can be rationalized via a rather simple electrostatic interaction model. At $\mathrm{pH}$ 9, both L-lysine $\left(\mathrm{p} K_{\mathrm{a}}\right.$ of the residue is 10.28) and $\mathrm{L}$-arginine ( $\mathrm{p} K_{\mathrm{a}}$ of the residue is 13.28) are charged, whereas L-histidine is uncharged $\left(\mathrm{p} K_{\mathrm{a}}\right.$ of the residue is 5.97). ${ }^{42}$ As the ferrihydrite surface is positively charged, ${ }^{28,43,44}$ L-lysine and L-arginine, which also carry positive charges, are repelled from the ferrihydrite surface and therefore show a weaker interaction with the ferrihydrite surface than L-histidine.

Of the basic amino acids, only L-histidine is uncharged and contains donor atoms, which can interact more strongly with the inorganic surface of ferrihydrite. L-Histidine is thus the better stabilizer for the unstable ferrihydrite than the positively charged 
TABLE 2: Size (Anisotropy) of the Particles Analysis of the Samples Determined from Rietveld Refinement ${ }^{a}$

\begin{tabular}{|c|c|c|c|}
\hline & $1 \mathrm{mM}$ & $10 \mathrm{mM}$ & $100 \mathrm{mM}^{b}$ \\
\hline control sample & & $\begin{array}{c}\text { mag: } 566.06(0.36) \\
\text { goe: } 64.47(0.15)\end{array}$ & \\
\hline L-valine & mag: $209.27(0.15)$ & mag: $123.89(0.08)$ & $\begin{array}{l}\text { mag: } 27.07(0.02) \\
\text { goe: } \mathrm{n} / \mathrm{a}^{c} \\
\text { lep: } 84.48(0.06)\end{array}$ \\
\hline L-lysine & mag:172.56 (0.11) & $\begin{array}{l}\text { mag: } 148.49(0.3) \\
\text { goe: } 148.39(0.3)\end{array}$ & $\begin{array}{l}\text { mag: } 27.07(0.02) \\
\text { goe: } \mathrm{n} / \mathrm{a}^{c} \\
\text { lep: } 84.48(0.12)\end{array}$ \\
\hline L-methionine & mag: 291 & $\begin{array}{l}\text { mag: } 62 \\
\text { goe: } 62.24\end{array}$ & $\begin{array}{l}\text { mag: } 30 \\
\text { lep: } 44.59\end{array}$ \\
\hline L-asparagine & $\begin{array}{l}\text { mag: } 175.13(0.13) \\
\text { goe: } 24.73(0.04)\end{array}$ & mag: 62.97 (0.08) & $\begin{array}{l}\text { mag: } 55.42(0.06) \\
\text { goe: } 46.61(0.10) \\
\text { lep: } 69.10(0.10)\end{array}$ \\
\hline L-arginine & mag: $255.24(0.04)$ & $\begin{array}{l}\text { mag: } 65.46(0.06) \\
\text { goe: } 126.66(0.34)\end{array}$ & $\begin{array}{l}\text { mag: } 53.01(0.05) \\
\text { goe: } 35.66(0.06) \\
\text { lep: } 69.08(0.07)\end{array}$ \\
\hline L-histidine & mag: $294.24(0.02)$ & mag: $104.50(0.09)$ & fer: $n / a^{c}$ \\
\hline L-threonine & $\begin{array}{l}\text { mag: } 95.13(0.13) \\
\text { goe: } 13.95(0.01)\end{array}$ & $\begin{array}{l}\text { mag: } 44.04(0.2) \\
\text { goe: } 47.08(0.03) \\
\text { lep: } 80.27(0.13)\end{array}$ & fer: $\mathrm{n} / \mathrm{a}^{c}$ \\
\hline L-cysteine & mag: $231.69(0.17)$ & lep: $52.11(0.06)$ & $\mathrm{n} / \mathrm{a}^{c}$ \\
\hline
\end{tabular}

goe: $113.37(0.16)$

lep: $305.44(0.31)$ others and (2) even single amino acids exhibit an incomplete selectivity for certain crystal phases. We suggest that the charges and charge distribution on the different amino acids plays a key role in the mineralization process. Another important parameter for the stabilization of metastable iron oxides is the presence of donor atoms like (uncharged) nitrogen, oxygen, or sulfur atoms. The data suggest that the combination of different amino acids could lead to short peptides that are more specific crystal phase modifiers than individual amino acids. Possibly even mixtures of amino acids could enhance the effects observed here.

Acknowledgment. We thank Dr. M. Neuburger for help with the CSD searches, L. Mirolo for X-ray support, Prof. E. C. Constable for access to his IR spectrometer, Prof. L. Diamond for access to the Raman spectrometer, and the Swiss National Science Foundation for funding. A.T. thanks the Holcim Stiftung Wissen for a Habilitation Fellowship.
${ }^{a}$ Mag: magnetite, Goe: goethite, Lep: lepidocrocite, Fer: ferrihydrite, n/a: not applicable due to too low peak intensity or too broad reflections. Sizes are given in $\AA$. ${ }^{b}$ Maximum concentrations are $80 \mathrm{mM}$ for L-threonine and $60 \mathrm{mM}$ for L-histidine. ${ }^{c}$ Some values could not be determined due to too broad lines, where Rietveld refinement was not successful.

amino acids. This finding is supported by earlier experiments, ${ }^{28}$ where Matrajt and Blanot have shown that L-histidine and L-threonine adsorb much more efficiently on ferrihydrite than the other amino acids used in our study.

Our data support this earlier work, but they also show that uncharged amino acids like L-histidine, L-cysteine, and Lthreonine appear to be the better stabilizers for unstable iron oxides. In addition, our study shows that higher amino acid concentrations in some cases stabilize increasingly less stable crystal phases. The most obvious example is L-threonine, where at $1 \mathrm{mM}$, ca. $50 \%$ of the sample are goethite, at $10 \mathrm{mM}$, the fraction of goethite is lower, but an additional ca. 50\% of lepidocrocite form, and at $100 \mathrm{mM}$ only ferrihydrite is observed. A similar argument can be made for L-cysteine, although there, also, the disulfide formation must be taken in account. At lower concentrations there is a diverse group of amino acids, which can trap metastable iron oxide crystal phases, however, usually not as single phase materials.

The above scenario of adsorption and trapping of kinetically favored metastable crystal phases is supported by crystallite size analysis, Table 2. For example, goethite formed in $10 \mathrm{mM}$ solutions of L-threonine has a coherence length of $47 \AA$. Goethite precipitated with $10 \mathrm{mM}$ solutions of L-lysine has a coherence length of $148 \AA$. This suggests a strong affinity of L-threonine toward strongly hydrated iron (hydr)oxides, which leads to smaller crystallite size. This further corroborates stabilization via amino acid adsorption and clearly shows that there are large affinity differences between the amino acids and the different crystal phases. TGA and IR further support this finding by showing evidence for amino acid incorporation into the precipitates.

\section{Conclusion}

In summary, our study shows that (1) there are amino acids that are more efficient iron oxide crystal phase modifiers than

\section{References and Notes}

(1) Bauerlein, E. Angew. Chem., Int. Ed. 2003, 42, 614.

(2) Bauerlein, E. Biomineralization - Progress in Biology, Molecular Biology and Application; Wiley-VCH: Weinheim, Germany, 2004.

(3) Cornell, R. M.; Schwertmann, U. The Iron Oxides: Structure, Properties, Reactions, Occurrences and Uses; Wiley-VCH; Weinheim, Germany, 2003.

(4) Lang, C.; Schüler, D.; Faivre, D. Macromol. Biosci. 2007, 7, 144.

(5) Gupta, A. K.; Gupta, M. Biomaterials 2005, 26, 3995.

(6) Tiefenauer, L. X. Magnetic nanoparticles as contrast agents for medical diagnosis. In Nanotechnology in Biology and Medicine; Vo-Dinh, T., Ed.; CRC Press LLC: Boca Raton, FL, 2007; pp 29/1.

(7) Douziech-Eryrolles, L.; Marchais, H.; Herve, K.; Munnier, E.; Souce, M.; Linassier, C.; Dubois, P.; Chourpa, I. Int. J. Nanomed. 2007, 2, 541.

(8) Lu, A.-H.; Salabas, E. L.; Schüth, F. Angew. Chem., Int. Ed. 2007, 46,1222 565.

(9) Mann, S.; Hannington, J. P.; Williams, R. J. P. Nature 1986, 324, (10) Laberty, C.; Navrotsky, A. Geochim. Cosmochim. Acta 1998, 62, 2905

(11) Banfield, J. F.; Welch, S. A.; Zhang, H.; Thomsen Ebert, T.; Penn, R. L. Science 2000, 289, 751.

(12) McGuire, M. M.; Edwards, K. J.; Banfield, J. F.; Hamers, R. J. Geochim. Cosmochim. Acta 2001, 65, 1243.

(13) Majzlan, J.; Lang, B. E.; Stevens, R.; Navrotsky, A.; Woodfield, B. F.; Boerio-Goates, J. Am. Mineral. 2003, 88, 846.

(14) Majzlan, J.; Navrotsky, A.; Schwertmann, U. Geochim. Cosmochim. Acta 2004, 68, 1049.

(15) Nesterova, M.; Moreau, J.; Banfield, J. F. Geochim. Cosmochim. Acta 2003, 67, 1177.

(16) Chan, C. S.; De Stasio, G.; Welch, S. A.; Girasole, M.; Frazer, B. H.; Nesterova, M. V.; Fakra, S.; Banfield, J. F. Science 2004, 303, 1659. (17) Waychunas, G. A.; Kim, C. S.; Banfield, J. F. J. Nanoparticle Res. 2005, 7, 409.

(18) Mazeina, L.; Deore, S.; Navrotsky, A. Chem. Mater. 2006, 18, 1830.

(19) Mazeina, L.; Navrotsky, A. Clays Clay Minerals 2005, 53, 113.

(20) Matsunaga, T.; Suzuki, T.; Tanaka, M.; Arakaki, A. Trends Biotechnol. 2007, 25, 182.

(21) Staniland, S.; Ward, B.; Harrison, A.; van der Laan, G.; Telling, N. Proc. Natl. Acad. Sci. USA 2007, 104, 19524.

(22) Faivre, D.; Böttger, L. H.; Matzanke, B. F.; Schüler, D. Angew. Chem., Int. Ed. 2007, 46, 8495.

(23) Navrotsky, A.; Mazeina, L.; Majzlan, J. Science 2008, 319, 1635.

(24) Brown, S. Proc. Natl. Acad. Sci. U.S.A. 1992, 89, 8651.

(25) Brown, S.; Sarikaya, M.; Johnson, E. J. Mol. Biol. 2000, 299, 725.

(26) Arakaki, A.; Webb, J.; Matsunaga, T. J. Biol. Chem. 2003, 278, 8745 .

(27) Prozorow, T.; Mallapragada, S. K.; Narasimhan, B.; Wang, L.; Palo, P.; Nilsen-Hamilton, M.; Wiiliams, T. J.; Bazylinski, D. A.; Prozorow, R.; Canfield, P. Adv. Funct. Mater. 2007, 17, 951.

(28) Matrajt, G.; Blanot, D. Amino Acids 2004, 26, 153. 
(29) Sarikaya, M.; Tamerler, C.; Jen, A. K. Y.; Schulten, K.; Baneyx, F. Nat. Mater. 2003, 2, 577.

(30) Gerstel, P.; Hoffmann, R. C.; Lipowsky, P.; Jeurgens, L. P. H.; Bill, J.; Aldinger, F. Chem. Mater. 2006, 18, 179.

(31) Bauermann, L. P.; Bill, J.; Aldinger, F. J. Phys. Chem B 2006, 110, 5182.

(32) Taubert, A.; Palms, D.; Glasser, G. Langmuir 2002, 18, 4488.

(33) Taubert, A.; Palms, D.; Weiss, Ö.; Piccini, M.-T.; Batchelder, D. N. Chem. Mater. 2002, 14, 2594.

(34) Taubert, A.; Kübel, C.; Martin, D. C. J. Phys. Chem B 2003, 107, 2660 .

(35) Rao, P. V.; Holm, R. H. Chem. Rev. 2004, 104, 527.

(36) Schmitt, B.; Brönnimann, C.; Eikenberrya, E. F.; Gozzo, F.;

Hörmann, C.; Horisberger, C.; Patterson, B. Nuclear Instrum Methods Phys Res A 2003, 501, 267.

(37) http://www-llb.cea.fr/fullweb/fp2k/fp2k.htm, August, 2006.
(38) Oner, M.; Norwig, J.; Meyer, W. H.; Wegner, G. Chem. Mater. 1998, 10, 460 .

(39) Wegner, G.; Baum, P.; Muller, M.; Norwig, J.; Landfester, K. Macromol. Symp. 2001, 175, 349.

(40) Nobuyuki, T.; Kolthoff, I. M.; Stricks, W. J. Am. Chem. Soc. 1955, $77,1996$.

(41) Chang, S.-G.; Littlejohn, D.; Liu, D. K. Ind. Eng. Chem. Res. 1988, $27,2156$.

(42) Windholz, M.; Budavari, S.; Stecher, P. G. The Merck Index, 8th ed.; Merck: Rahway, NJ, 1968.

(43) Charlet, L.; Manceau, A. A. J. Colloid Interface Sci. 1992, 148, 425.

(44) Davis, J. A.; Leckie, J. O. J. Colloid Interface Sci. 1978, 67, 90. 